\title{
Neuroinflammatory modulators of oligodendrogenesis
}

\author{
Ana Armada-Moreira ${ }^{1,2^{*}}$, Filipa F. Ribeiro ${ }^{1,2^{*}}$, Ana M. Sebastião ${ }^{1,2}$, Sara Xapelli, ${ }^{1,2}$ \\ ${ }^{1}$ Instituto de Farmacologia e Neurociências, Faculdade de Medicina da Universidade de Lisboa, 1649-028 Lisboa, Portugal. \\ ${ }^{2}$ Instituto de Medicina Molecular, Faculdade de Medicina da Universidade de Lisboa, 1649-028 Lisboa, Portugal.
}

\section{A B S T R A C T}

Oligodendrocytes are key neural cells that are responsible for producing myelin sheaths that wrap around neuronal axons in the central nervous system. Myelin is essential to insulate neurons and maintain a fast and saltatory propagation of action potentials along the axon. However, oligodendrocytes are very susceptible to damage, and thus demyelination may arise from a brain lesion or a neurodegenerative disorder. Consequently, demyelination produces a loss of axonal insulation leading to sensory or motor neuron failure. During adulthood, there are two main sources of oligodendrocytes: parenchymal oligodendrocyte precursor cells (OPCs) and subventricular zone derived OPCs. In this review, we will discuss oligodendrogenesis derived from these two sources, and also highlight their main extrinsic and intrinsic modulators. In addition, the neuroinflammatory mediators of oligodendrogenesis will also be assessed.

Key words: Demyelination, inflammation, neural stem cells, oligodendrocyte, remyelination

\section{INTRODUCTION}

Oligodendrocytes are the myelin-forming cells of the central nervous system (CNS). They are the last brain cells to be generated during development, making myelination a late event in brain maturation. ${ }^{[1]}$ Their cholesterol-rich membrane loops around neuronal axons creating a myelin sheath, which is a multilamellar spiral structure that protects neurons, ensures their survival $^{[1]}$ and provides electrical insulation that enables faster transmission of action potentials along axons. ${ }^{[2]}$ Oligodendrocytes are essential for proper brain functioning and are easily affected by oxidative stress, so that demyelination is often a secondary event to brain lesions or pathologies. ${ }^{[1]}$ However, new oligodendrocytes are continuously generated during adulthood, which restore insulation of demyelinated axons and/or remodel existing myelin, an important role for functional plasticity, learning, and memory

\footnotetext{
*Authors contributed equally

Corresponding Author: Dr. Sara Xapelli, Instituto de Medicina Molecular, Faculdade de Medicina da Universidade de Lisboa, Av. Professor Egas Moniz,

1649-028 Lisboa, Portugal.

E-mail: sxapelli@medicina.ulisboa.pt
}

\begin{tabular}{|l|l|}
\hline \multicolumn{2}{|c|}{ Access this article online } \\
\hline Quick Response Code: & Website: \\
\hline & www.nnjournal.net \\
\hline & \\
\hline
\end{tabular}

formation. This process is called remyelination, one of the few spontaneous processes of regeneration that take place in the adult CNS. ${ }^{[3]}$ New oligodendrocyte production is therefore enhanced in response to a pathological insult such as demyelination. During the progression of a demyelinating disease, such as multiple sclerosis (MS), several inflammatory modulators are released by a variety of brain cells impacting the determination, proliferation, differentiation, migration, and maturation of oligodendrocyte precursor cells (OPCs), ultimately resulting in remyelination. New myelinating oligodendrocytes are derived from two main cell sources: early postnatal-derived OPCs that are present all over the brain parenchyma; ${ }^{[4]}$ and new OPCs that are continuously originated from a distinct group of transit-amplifying progenitors in the subventricular zone (SVZ) of the lateral walls of the lateral ventricles. ${ }^{[4,5]}$ In response to demyelination, both parenchymal OPCs and SVZ-derived OPCs produce new oligodendrocytes to recover from myelin loss. ${ }^{[5]}$

Oligodendrogenesis is a process that is regulated by extrinsic and intrinsic factors. The main external stimuli are morphogens, growth factors, and extracellular

This is an open access article distributed under the terms of the Creative Commons Attribution-NonCommercial-ShareAlike 3.0 License, which allows others to remix, tweak, and build upon the work non-commercially, as long as the author is credited and the new creations are licensed under the identical terms.

For reprints contact: nn_editor001@nnjournal.net

Cite this article as: Armada-Moreira A, Ribeiro FF, Sebastião AM, Xapelli S. Neuroinflammatory modulators of oligodendrogenesis. Neuroimmunol Neuroinflammation 2015;2:263-73.

Received: 14-02-2015; Accepted: 15-06-2015 
matrix elements while the internal stimuli important for oligodendrocyte formation are transcription factors and epigenetic regulators. Therefore, studying modulators capable of stimulating OPCs are of paramount importance and fundamental for future therapies concerning inflammatory and neurodegenerative disorders in which myelin sheaths are affected.

\section{OLIGODENDROGENESIS FROM OPCs DURING DEVELOPMENT AND IN THE ADULT BRAIN PARENCHYMA}

During CNS development, and also throughout adulthood, oligodendrogenesis is derived from OPCs. OPCs are a subtype of glial cell, characterized by the expression of the platelet-derived growth factor receptor $\alpha$ (PDGFR $\alpha$ ), and the neuron-glial antigen 2 (NG2) proteoglycan [Figure 1]. ${ }^{[6]}$ Other known markers for these cells are the $\mathrm{O} 4$ antigen and the transcription factors Olig1, Olig2, and Nkx 2.2. ${ }^{[7]}$ It should be noted that, these markers can be expressed in other cells, a combination of markers should be used to unambiguously identify OPCs. ${ }^{[1]}$ In the adult brain, OPCs comprise $3-8 \%$ of the total number of cells ${ }^{[8]}$ and are prevalent in the hippocampus and in all layers of the neocortex. ${ }^{[9]}$

In the developing forebrain of mice, the entire oligodendrocyte population is generated from three phases of OPC proliferation and migration. The first phase occurs at embryonic day 12.5 (E12.5) and consists of a "wave" of OPC production, originated from ventral ganglionic eminences. ${ }^{[10,11]}$ At E15.5, the second phase takes place, emerging from the lateral and caudal ganglionic eminences. ${ }^{[12]}$ Finally, the third phase happens after birth, with origin in the cortex. ${ }^{[12]}$ These three phases are responsible for the generation of most adult oligodendrocytes in mice, which will migrate and populate most of the future brain..$^{[1]}$

In human CNS development, oligodendrocyte differentiation and maturation follow similar paths to rodents. ${ }^{[13]}$ This process has its beginning in the second trimester of gestation and spans into birth and adulthood. ${ }^{[14,15]}$ Specifically, at 9 gestation weeks, early OPCs (NG2 and PDGFR $\alpha$ positive) arise from the ganglionic eminence and migrate to the cortex in the following weeks. Late OPCs, which show O4 immunoreactivity, are first detected in a small percentage at 15 gestation weeks, gaining more density in midgestation (c. 20-22 gestation weeks), especially in the subplate layer directly under the cortical plate. Finally, myelin basic protein-positive oligodendrocytes are rare at midgestation but show a steady population growth from that point on. Indeed, the first myelin sheaths can be found around 18 gestation weeks in the thalamus, spreading to the internal capsule at 21 gestation weeks. ${ }^{[15]}$

Given the nature of oligodendrocyte production, one question arises: are the OPCs involved in these different phases functionally equivalent? There is evidence that each phase of OPC production can lead to the myelination of distinct brain regions, ${ }^{[16]}$ suggesting the existence of functionally different subpopulations of OPCs that serve separate functions. In fact, a study conducted in mice targeted differentially ventrally-derived OPCs (vOPCs) and dorsally-derived OPCs (dOPCs), as well as the oligodendrocytes generated by each class of OPCs (vOLs and dOLs respectively). This study shows that while vOPCs and dOPCs appear to have the same electrical properties, their migration and settling patterns are significantly different, to the point that vOLs and dOLs populate different forebrain and spinal cord regions at different timepoints during development (for example, while in adulthood the corticospinal and rubrospinal tracts are myelinated by dOLs; during early postnatal life, these regions are actually myelinated by vOLs). ${ }^{[16]}$ On the other hand, it has been shown that, if one of these subpopulations is eliminated, neighboring OPCs of different origins rapidly migrate and proliferate to generate the regular number of oligodendrocytes in the mature brain, ${ }^{[12]}$ which could imply that the subpopulations of OPCs are functionally equivalent.

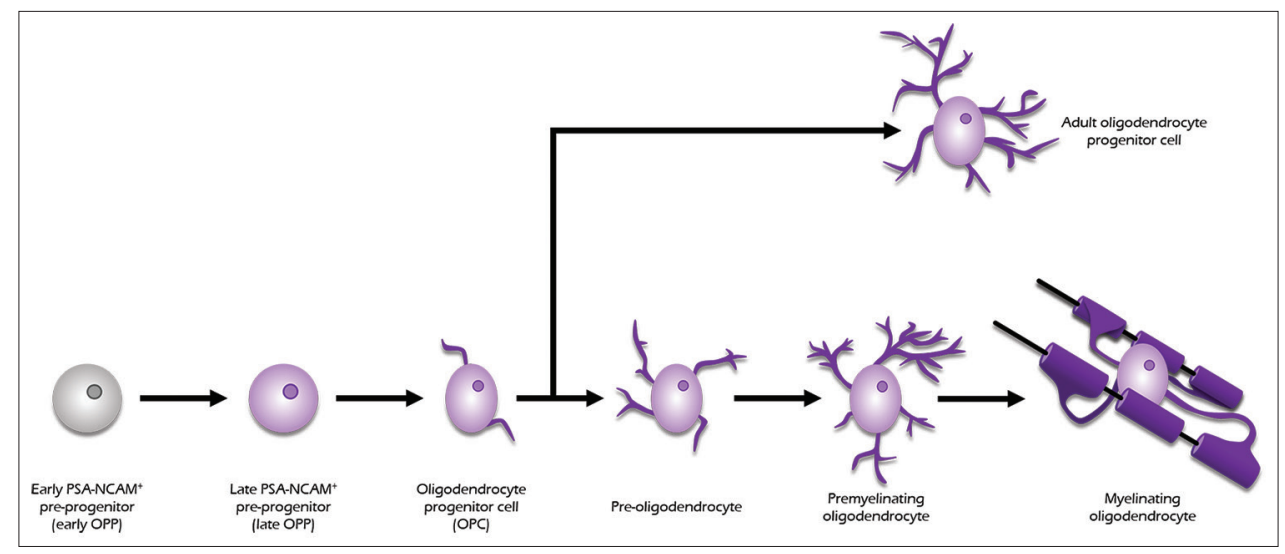

Figure 1: Diagram of the oligodendrocytic lineage progression: from early oligodendrocyte precursor cell to functioning mature myelinating oligodendrocyte 
After CNS development, a small fraction of OPCs remains undifferentiated, in an immature slowly proliferative or quiescent state. ${ }^{[17]}$ These adult OPCs are morphologically equivalent and express the same markers as the OPCs present during development. ${ }^{[18]}$ However, they differ from the developing OPCs in growth factor responsiveness, migration capacity, and cell cycle length. ${ }^{[19-21]}$ Their cell density, although stable throughout adult life, is higher in white matter than in gray matter. ${ }^{[22,23]}$ Indeed, it has been shown that adult OPCs present a higher rate of proliferation in white matter, which is a possible explanation for the difference in cell density. ${ }^{[22]}$ It is possible to further divide white matter OPCs and gray matter OPCs by their characteristics. While white matter OPCs are proliferative and eventually lead to adult oligodendrogenesis, gray matter OPCs remain quiescent and immature. ${ }^{[22]}$

Given these findings, could adult OPCs be a heterogeneous population, possibly with several distinct functions? Some studies show that the different characteristics observed in adult OPCs can be the result of environmental signals. Specifically, gray matter environment is described as an inhibitor of OPC proliferation and differentiation while white matter environment seems to favor OPC maturation. ${ }^{[17,22,23]}$ These differences may be linked to intrinsic cell mechanisms or to environmental cues. While there seem to be differences in the local microenvironment surrounding OPCs in white and gray matter, the different characteristics of white matter and gray matter OPCs can also be explained by intrinsic mechanisms, such as receptor desensitization. For instance, it is known that, in the developing spinal cord, PDGF-A mRNA has higher expression in the gray matter, ${ }^{[24]}$ which can lead to desensitization of the receptor (PDGFR $\alpha$ ) and prolonged impairment of gray matter OPCs maturation. ${ }^{[25]}$ However, there are indeed molecular differences between white matter OPCs and gray matter OPCs, namely in the resting membrane potential and ion channels expression. ${ }^{[26,27]}$ Concerning the ion channels, two subpopulations of adult OPCs have been described: one completely devoid of voltage-gated $\mathrm{Na}^{+}$channels, and another with functional channels, able to react to action potentials. Consequently, this second subtype can sense neuronal activity through axonal input and is more sensitive to ischemia. ${ }^{[26]}$ Another study corroborating the existence of functionally different subtypes shows that white matter OPCs can generate myelinating oligodendrocytes even if they are transplanted into other brain regions. Gray matter OPCs, in contrast, remain less efficient even if transplanted into white matter. ${ }^{[28]}$ Therefore, it seems that white matter OPCs are more prepared to generate new myelinating oligodendrocytes than gray matter OPCs. What is the role of OPCs in gray matter remains a question to be explored.

In response to a demyelinating insult, the remyelitation process is activated. New myelinating oligodendrocytes are mainly generated from early postnatal-derived OPCs that are present in the brain parenchyma. ${ }^{[4]}$ In a first phase, quiescent or slow-dividing OPCs are recruited to the damaged areas OPCs start to proliferate, migrate, and populate the demyelinated area. In a second phase, the recruited OPCs start to differentiate into mature oligodendrocytes as they form myelin sheaths around demyelinated axons. ${ }^{[29]}$ Oligodendrocytes derived from parenchymal OPCs are only able to migrate short distances, just populating damaged areas in the proximity of their progenitor cells..$^{[5]}$

\section{OLIGODENDROGENESIS DERIVED FROM ADULT SUBVENTRICULAR ZONE NEURAL STEM CELLS}

After birth, OPCs can be produced by adult neural stem cells (NSC), which are self-renewing, multipotent cells that generate most of the cells of the nervous system, such as neurons, astrocytes, and oligodendrocytes. ${ }^{[30]}$ These NSCs can divide in three different ways: symmetrically, originating in two new NSCs (expansion, symmetrical self-renewal); asymmetrically, originating one NSC and one differentiated cell (maintenance, asymmetrical self-renewal); or symmetrically, originating two differentiated cells (extinction, symmetrical commitment). Depending on the activation of specific signaling pathways and the presence of differentiation-inducing molecules, NSCs are capable of differentiating into cells of neuronal (neurogenesis) and glial (gliogenesis) lineages, particularly oligodendrocytes (oligodendrogenesis). ${ }^{[31]}$

Neural stem cells exist in discrete regions of the adult mammalian brain where neurogenesis and oligodendrogenesis are highly regulated. ${ }^{[32]}$ The brain regions where these processes take place, that is where the NSC pools can be encountered, are called neurogenic niches. In adulthood, there are two main neurogenic niches in the brain: the SVZ of the lateral ventricles, and the subgranular zone of the dentate gyrus (DG) of the hippocampus. ${ }^{[33]}$

In the SVZ, the NSC pool comprises type B cells, which are quiescent NSCs that originate type $\mathrm{C}$ cells, which are fast dividing transient amplifying cells. ${ }^{[34]}$ Most of these C cells will then differentiate into neuroblasts (type A cells), migrate along the rostral migratory stream ${ }^{[35]}$ to the olfactory bulb, and terminally differentiate into interneurons. ${ }^{[36,37]}$ SVZ-derived oligodendrogenesis originates from a minority of $\mathrm{C}$ cells that do not follow the previously explained cellular fate. Instead, they 
produce OPCs, which migrate radially out of the SVZ into the surrounding cortex and white matter [Figure 2]. . $^{[5,38,39]}$

It should be noted that one NSC can generate either oligodendrocytes or neurons exclusively ${ }^{[13]}$ and that the number of oligodendrocytes produced by the SVZ NSC pool is significantly inferior to the number of olfactory interneurons. ${ }^{[5]}$ The relative quantity of oligodendrocytes and neurons is area dependent: while in the posterior zone of the SVZ, the ratio is one oligodendrocyte to three neurons; in the rostral zone, this ratio is 1:30. ${ }^{[5]}$ The ratio also changes dorsoventrally, due to environmental cues. The dorsal part of the SVZ is Wnt enriched, which favors OPC commitment. ${ }^{[13]}$ On the other hand, the ventral part is more exposed to bone morphogenic proteins (BMP), which inhibits OPC specification. ${ }^{[40]}$

Contrary to the parenchymal OPCs, SVZ-derived OPCs, although a minority in the brain, can migrate long distances into the corpus callosum, striatum, and fimbria fornix, where they continue to divide or differentiate into mature myelinating and nonmyelinating oligodendrocytes. ${ }^{[5]}$ Adult SVZ progenitor cells mostly generate neuronal lineage cells and only a few oligodendrocytes; however, progenitor cells show some lineage plasticity in pathological conditions. In a demyelination context, OPC production in SVZ is favored to the detriment of neuronal precursor cells. These OPCs then migrate to the affected areas, where they differentiate into

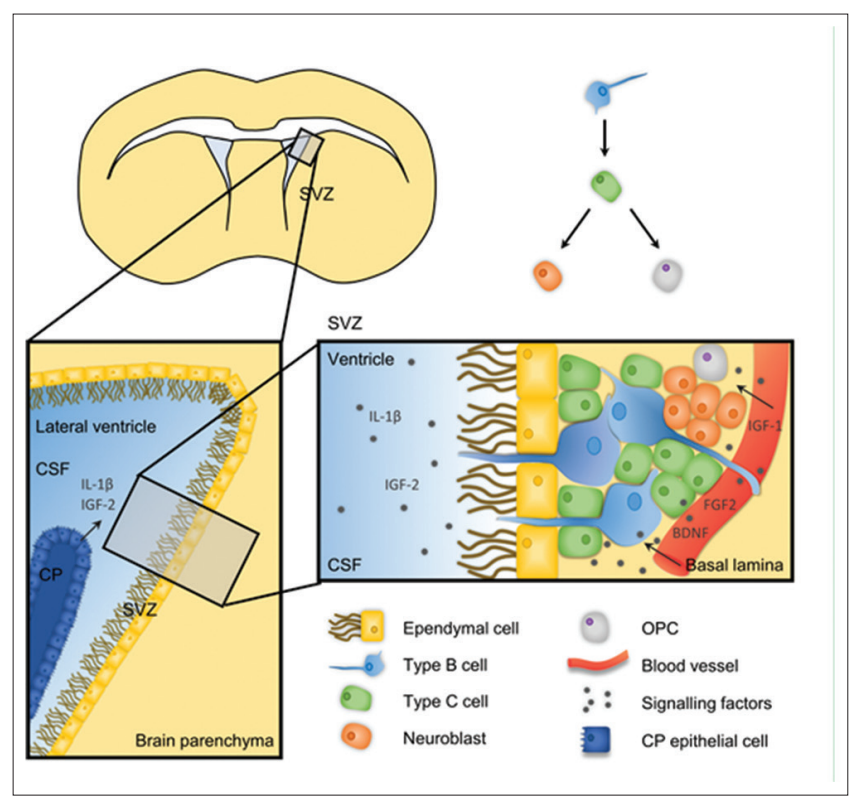

Figure 2: Schematic representation of the adult subventricular zone (SVZ) neurogenic niche. SVZ lines the lateral ventricles and is comprised of three main cell types: the multipotent type $B$ cells that give rise to type $C$ cells (fast dividing transient amplifying cells) that generate type A neuroblasts. Type B cells interact basally with blood vessels and apically with the cerebrospinal fluid (CSF). The composition of the CSF is modified by the choroid plexus, a thin vascularized membrane mainly composed by epithelial cells, which secretes several cytokines and trophic factors to the CSF oligodendrocytes, contributing to the remyelination process [Figure 3]. ${ }^{[4,5,41,42]}$

The generation of new oligodendrocytes from the SVZ is possible because adult NSCs, from which OPCs are derived, are embedded in the specialized and diverse microenvironments of the SVZ niche, which is responsible for regulating NSCs and their progenies' self-renewal and differentiation by receiving information from the brain and other tissues. ${ }^{[43-45]}$

The first specialized microenvironment is the apical ependymal compartment where slow-dividing type $\mathrm{B}$ cells are in direct contact with the cerebrospinal fluid (CSF) present in the space of the lateral ventricles, through a specialized apical process surrounded by ependymal cells. ${ }^{[43,44,46]}$ The adult choroid plexus (CP) expresses and secretes to the CSF not only numerous trophic factors but also cytokines, which can influence the behavior of SVZ progenitor cells, modulating the self-renewal capacity, proliferation, and differentiation [Figure 2]. ${ }^{[43,44]}$ Interleukin-1 $\beta$ (IL-1 $\beta$ ) is one of the cytokines that are secreted and regulated by $\mathrm{CP}$, which acts on type B cells through binding to IL-1 receptors to up-regulate vascular cell adhesion molecule 1 expression, modulating type $\mathrm{B}$ cells adherence to the SVZ niche. Insulin-like growth factor 2 (IGF-2) is also present in the adult CSF and regulates SVZ progenitor proliferation. ${ }^{[44]}$ Moreover, CP also secretes guidance molecules, such as chemorepulsive factors and chemoattractants, which regulate SVZ NSCs and their progenies' migration. ${ }^{[42]} \mathrm{CP}$ changes its secretome under pathological conditions, leading to a different CSF cellular and molecular composition that will then influence the SVZ niche population. For example, during peripheral tissue inflammation, inflammatory information from the blood can have an impact in the CNS. ${ }^{[47,48]}$ Peripheral inflammation elicits the up-regulation of cytokines, adhesion factors, and signaling pathway genes, such as tumor necrosis factor- $\alpha$ (TNF- $\alpha$ ), IL- $1 \beta$, and small inducible cytokine A2 transcripts that are under the regulation of the NF- $\kappa B$ cascade, in the CP. ${ }^{[47]}$ Then the CP, through changes in CSF composition, will affect the SVZ niche population.

The second SVZ niche component is the basal vasculature, composed of blood vessels and a basal lamina rich in laminin. ${ }^{[42]}$ Here, type B cells have a long specialized basal process through which they interact with blood vessels, and fast-dividing/transit-amplifying type $\mathrm{C}$ cells are also in very close proximity to blood vessels. $^{[43-46]}$ Endothelial cells secrete several diffusible signals, such as fibroblast growth factor-2 (FGF2), 


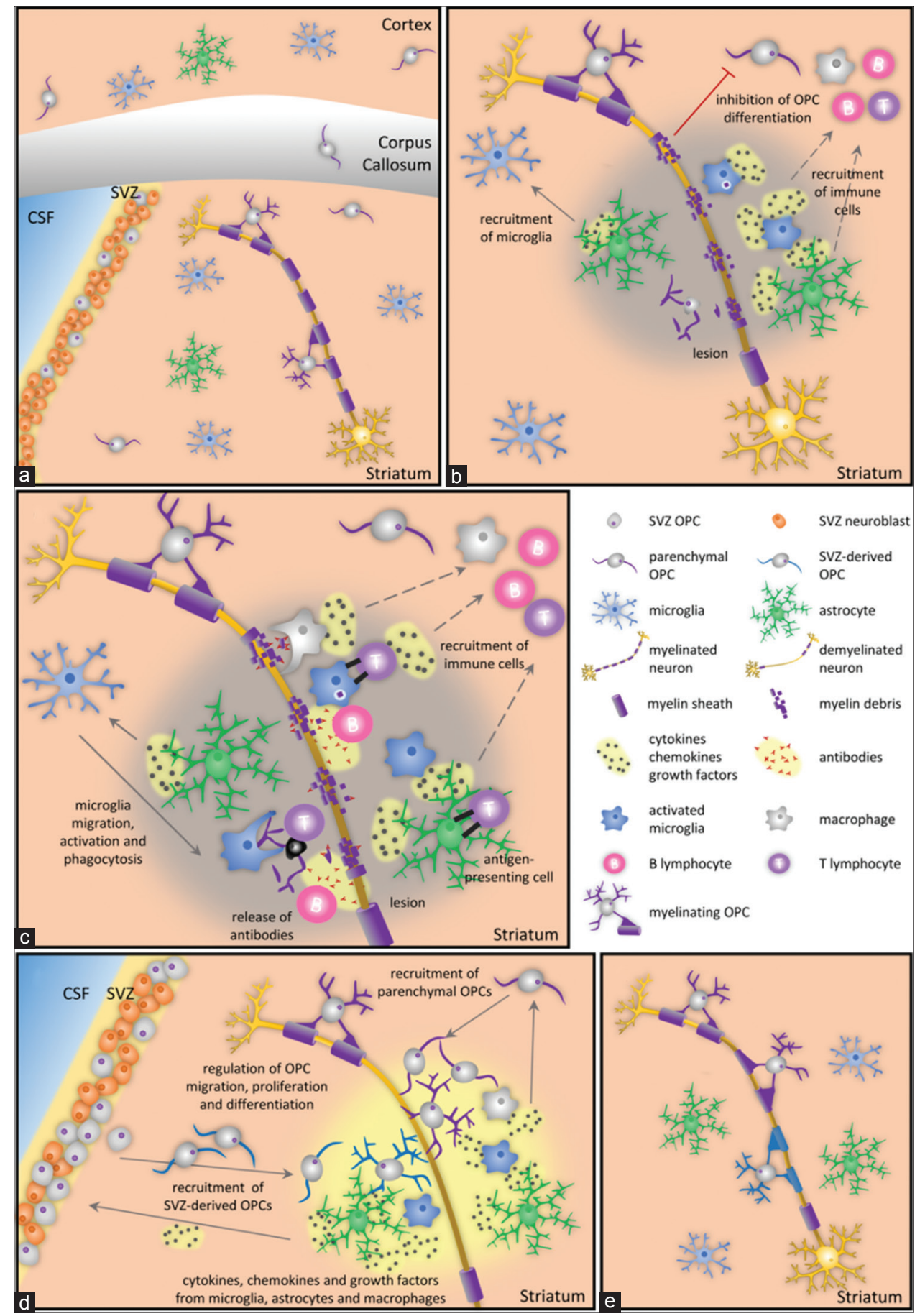

Figure 3: Schematic representation of the demyelination and remyelination processes. (a) in a basal condition, type A neuroblasts and oligodendrocyte precursor cells (OPCs) are continuously generated from neural stem cells, with neuroblasts being the great majority progeny; (b) after a demyelinating episode, nearby astrocytes and microglia are activated and release inflammatory mediators, increasing the permeability of the blood-brain barrier (BBB). By releasing chemokines, astrocytes recruit more microglial cells to the demyelinated area; (c) which phagocyte dead cells and myelin debris, as do macrophages that have crossed the BBB. Astrocytes and macrophages act as antigen-presenting cells to T lymphocytes that are then activated and attack the myelin sheath and dying cells. B lymphocytes produce autoantigens against myelin antigens functioning as opsonins; (d) microglia, macrophages, and astrocytes release mediators that mobilize parenchymal OPCs to proliferate, migrate, and differentiate into new myelinating oligodendrocytes in the demyelinated area. After a demyelinating episode, OPC production in the subventricular zone (SVZ) is favored in detriment of neuronal precursor cells. These SVZ-derived OPCs migrate to the demyelinated areas where they differentiate into mature myelinating oligodendrocytes; (e) new myelinating oligodendrocytes form a thinner myelin sheath around the demyelinated axon

IGF-1, brain-derived neurotrophic factor (BDNF), chemokines, among others, which also influence stem cell self-renewal, proliferation, and fate determination in the SVZ [Figure 2]..$^{[44-46,49]}$ In addition, cerebral endothelial cells promote differentiation of SVZ NSCs into oligodendrocytes, being important for the proliferation and migration of OPCs. ${ }^{[42]}$
The extracellular matrix composition of the vascular basal lamina makes the basal lamina an important integration site for the exchange of signals between the SVZ progenitors and the main compartments of the SVZ niche, the vasculature and the CSF, because it provides, stores, and compartmentalizes growth factors and cytokines. ${ }^{[42,45]}$ 
By changing the composition of CSF or the blood stream, it would be possible to modulate proliferation and or differentiation of SVZ progenitors with an impact on demyelinating diseases; however, these modifications should be tightly regulated to maintain brain homeostasis.

\section{MODULATORS OF OLIGODENDROGENESIS}

\section{Extrinsic factors}

The extrinsic factors include morphogens, growth factors, and signaling molecules delivered through blood vessels or associated with the extracellular matrix. For instance, during the development of both the brain and spinal cord, the relative levels of Sonic hedgehog (Shh), BMP, and Wnt/ $\beta$-catenin have been shown to play roles in oligodendrocyte determination. ${ }^{[1]}$ The motoneuron domain $(\mathrm{pMN})$ is a restricted domain of the ventral ventricular zone of the embryonic spinal cord, and in mice, cells in this domain express the transcription factors Olig1 and Olig2. ${ }^{[50]}$ In this zone, Olig2 expression is crucial for the production of motoneurons and oligodendrocytes. In order for this transcription factor to induce oligodendrogenic cell fate instead of neuronal differentiation, a switch must occur. ${ }^{[1]}$ As seen in both mice and zebrafish, this switch is highly dependent on the level of Shh in the environment ${ }^{[51]}$ and on the Notch/delta pathway, which restricts the production of motoneurons, thus allowing oligodendrocyte determination..$^{[52]}$ On the other hand, this switch is repressed if high level of BMPs and Wnt are locally present. ${ }^{[53]}$ It has also been shown that, during brain development, Shh promotes the generation of ventrally derived OPCs, ${ }^{[11]}$ while Wnt $/ \beta$-catenin and BMPs inhibit it. Curiously, in the adult brain, there is an apparent contradiction since Wnt3 (from the Wnt family) promotes oligodendrocyte specification in the SVZ. ${ }^{[13]}$

Other extrinsic factors modulate oligodendrogenesis in the adult SVZ. Evidence shows that both factors secreted by blood vessels and factors connected to the extracellular matrix are capable of favoring OPC commitment. ${ }^{[13,54,55]}$ One of these factors is laminin, an element of the extracellular matrix. A study in mice shows that the elimination of laminin $\alpha 2$-subunit leads to a reduction of the OPC population in the SVZ. ${ }^{[56]}$ Other trophic factors, such as PDGF ${ }^{[57,58]}$ and epidermal growth factor (EGF), ${ }^{[59,60]}$ contribute indirectly to oligodendrocyte lineage determination, through promoting OPC proliferation and maturation. Additionally, IGF-1 also contributes to oligodendrogenesis by blocking BMP signaling, both in vivo and in vitro [Table 1]. ${ }^{[61]}$

Intrinsic factors

The intrinsic factors that modulate oligodendrogenesis include transcription factors and epigenetic
Table I: Main modulators of oligodendrogenesis in the adult brain

\begin{tabular}{|c|c|}
\hline Signal & Effect \\
\hline \multicolumn{2}{|l|}{ Extrinsic } \\
\hline \multicolumn{2}{|l|}{ Morphogens } \\
\hline$W n t^{[62]}$ & Stimulates NSC proliferation/self-renewal \\
\hline Notch $^{[63,64]}$ & $\begin{array}{l}\text { Required for NSC proliferation, } \\
\text { maintenance }\end{array}$ \\
\hline $\mathrm{Shh}^{[65]}$ & $\begin{array}{l}\text { Required for NSC maintenance and } \\
\text { OPC production }\end{array}$ \\
\hline SIRT1 ${ }^{[58]}$ & Inhibits oligodendrogenesis \\
\hline $\mathrm{BMP}^{[66]}$ & Inhibits oligodendrogenesis \\
\hline \multicolumn{2}{|l|}{ Growth factors } \\
\hline $\mathrm{EGF}^{[67]}$ & $\begin{array}{l}\text { Stimulates OPC proliferation and } \\
\text { migration }\end{array}$ \\
\hline $\mathrm{FGF}-2^{[68]}$ & Induces progenitor cell proliferation \\
\hline IGF-1[61] & Stimulates oligodendrocyte differentiation \\
\hline $\mathrm{PDGF}^{[58]}$ & $\begin{array}{l}\text { Induces OPC proliferation and } \\
\text { differentiation }\end{array}$ \\
\hline \multicolumn{2}{|l|}{$\begin{array}{l}\text { Extracellular matrix } \\
\text { elements }\end{array}$} \\
\hline Laminin $^{[56]}$ & Promotes OPC generation \\
\hline \multicolumn{2}{|l|}{ Intrinsic } \\
\hline \multicolumn{2}{|l|}{ Transcription factors } \\
\hline ASCL $1^{[69]}$ & Favors oligodendrocyte fate \\
\hline Nkx6.1/6.2 $2^{[70,71]}$ & $\begin{array}{l}\text { Required for oligodendrocyte and } \\
\text { motoneuron production in the pMN }\end{array}$ \\
\hline Sox8/9[72] & Promotes glial specification \\
\hline \multicolumn{2}{|l|}{ Epigenetic markers } \\
\hline miRNA-7a $a^{[73]}$ & Promotes OPC commitment \\
\hline Histone methylation ${ }^{[74]}$ & Favors OPC production \\
\hline Histone acetylation $^{[75]}$ & Inhibits OPC differentiation \\
\hline \multicolumn{2}{|c|}{$\begin{array}{l}\text { NSC: neural stem cell; OPC: oligodendrocyte precursor cell; pMN: progenitors } \\
\text { of motor neurons; Shh: sonic hedgehog; BMP: bone morphogenic protein; } \\
\text { EGF: epidermal growth factor; FGF-2: fibroblast growth factor-2; IGF-1: insulin-like } \\
\text { growth factor-1; PDGF: platelet-derived growth factor; ASCL1: achaete-scute } \\
\text { homolog } 1\end{array}$} \\
\hline
\end{tabular}

regulators. The main transcription factor involved in oligodendrocyte determination is Olig2. This basic helix-loop-helix (bHLH) factor is induced by $\mathrm{Shh}^{[76]}$ and expressed in every stage of oligodendrocyte maturation, from OPC to myelinating oligodendrocyte. ${ }^{[1]}$ In the majority of the CNS, inactivation of Olig2 during development leads to a reduction in OPCs. ${ }^{[76-78]}$ In contrast, overexpression of Olig2 in neuroepithelium leads to enhanced OPC production in the CNS. ${ }^{[79]}$ Furthermore, the presence of Olig2 is sufficient to reprogram rat and mouse fibroblasts into induced OPCs. ${ }^{\left[{ }^{[0,81]}\right.}$ Although this factor is crucial to oligodendrocyte differentiation, Olig2 knockout mice are still able to produce some OPCs in the hindbrain, possibly through Olig1 compensation. ${ }^{[76]}$

Another important transcription factor is Achaete-scute homolog 1 (Ascl1 or Mash1), which is also a bHLH factor. ${ }^{[1]}$ During development, absence of Ascl1 leads to a reduction of OPC production in the brain and spinal cord. ${ }^{[82,83]}$ However, this reduction can be compensated to normal values by Ascl2 and $3 \cdot{ }^{[83]}$ After birth, Ascl1 is only expressed in C cells and OPCs in the SVZ ${ }^{[69]}$ and similarly to what happens during CNS development, elimination of this transcription factor leads to decreased OPC generation. ${ }^{[69]}$ 
The Nkx and Sox families also play roles in oligodendrogenesis, even though they are not critical. ${ }^{[84]}$ Ablation of Nkx6.1/Nkx6.2 blocks the production of both oligodendrocytes and motoneurons in the pMN. ${ }^{[70,71]}$ Additionally, Sox9 knockout mice show deficits in glial specification, presenting a reduced number of oligodendrocytes and astrocytes. ${ }^{[72]}$ Furthermore, if there is a Sox8/Sox9 double inactivation, no oligodendrocytes are produced, which suggest that Sox8 and Sox9 serve redundant functions in relation to oligodendrogenesis. ${ }^{[72]}$

In the last few years, epigenetic modulation of oligodendrogenesis has been gaining some importance, namely regarding the modulation by microRNA and histone modifications. One of the most described microRNA in oligodendrogenesis is miRNA-7a. This miRNA is highly enriched in OPCs and overexpressing it in neuronal progenitors during brain development promotes OPC commitment, both in vivo and in vitro. ${ }^{[73]}$ In contrast, blocking miRNA-7a function inhibits OPC generation and favors neuronal progenitors. ${ }^{[73]}$

Histone modifications can also be important for oligodendrogenesis. For instance, it has been shown that oligodendrocyte production from NSCs, instead of other cellular fates, depends on histone deacetylases (Hdac) activity. ${ }^{[85]}$ Similarly, a study using Enhancer of zeste homolog 2 (Ezh2), a polycomb group protein involved in gene silencing through histone methylation, provided evidence that a higher rate of histone methylation (via Ezh2 overexpression) leads to an increase in oligodendrocyte production [Table 1]. ${ }^{[74]}$

\section{IMMUNE MEDIATORS OF OLIGODENDROGENESIS}

When white matter is damaged as a result of an infection, a trauma or a neurodegenerative disease such as MS or vascular dementia, microglia, the brain's innate immune cells, are activated. Microglia removes infectious agents and apoptotic cells, through phagocytosis and by producing reactive oxygen species (ROS), TNF- $\alpha$, nitric oxide (NO), IL-1 $\beta$, and prostaglandin E2. ${ }^{[86]}$ When microglia are chronically activated, sustained release of inflammatory factors, cytokines, and chemokines compromises the blood-brain barrier (BBB), resulting in vascular permeability to blood and circulating immune cells, such as $\mathrm{T}$ and $\mathrm{B}$ lymphocytes and macrophages, as well as recruitment of these peripheral immune cells to the lesion site. ${ }^{[87]}$ By recognizing their specific autoantigen presented by MHC class II molecules on the surface of antigen presenting cells, CD4 ${ }^{+} \mathrm{T}$ cells are activated and attack the myelin sheath. ${ }^{[87]}$ Antigens on MHC class I molecules also activate $\mathrm{CD}^{+} \mathrm{T}$ cells to attack myelin, demyelinated axons, and dying motoneurons through the activation of the perforin pathway, the delivery of granzymes into the cells, or by Fas-Fas ligand interactions. ${ }^{[86]}$ Additionally, B lymphocytes produce autoantibodies against myelin antigens, degrading myelin sheath. Because infiltrating effector T cells, microglia and macrophages release cytokines and chemokines, inflammation will be exacerbated and consequently more T cells, B cells, and innate immune cells will be recruited to the lesion site, contributing to chronic neuroinflammation, and neurodegeneration [Figure 3]. ${ }^{[87]}$

Neuroinflammatory responses can be deleterious for cell survival, resulting in irreversible extensive damage to the brain, especially if they are prolonged in time. ${ }^{[88]}$ However, they have also been described as having beneficial effects and as being critical for the activation of the brain repair process, such as for the remyelination program. As a result of white matter damage, there is an accumulation of apoptotic cells and myelin debris in the lesion site, which have been demonstrated to be inhibitory to axonal regeneration, as well as affecting OPC differentiation into mature myelinating oligodendrocytes. However, through phagocytosis of cellular debris and apoptotic cells, microglia and brain infiltrating macrophages function toward repairing the damaged tissue, by promoting a pro-regenerative environment, promoting OPC recruitment and differentiation, thus favoring remyelinaton and axonal regeneration. ${ }^{\text {[29,89-91] }}$ For instance, ROS hydrogen peroxide $\left(\mathrm{H}_{2} \mathrm{O}_{2}\right)$, released by macrophages and microglia, destroys damaged cells, affecting not only healthy surrounding cells, but also promoting proliferation and differentiation of NSCs into oligodendrocytes. ${ }^{[92]}$ Astrocytes have also been described to have an important, yet controversial, role in demyelinating diseases. Astrocytes have been shown to have an important role in both demyelination and remyelination..$^{[93-95]}$ On the one hand, because astrocytes are antigen-presenting cells and release cytokines and chemokines, they contribute to myelin damage through an immune-mediated demyelination by recruiting inflammatory cells, such as T lymphocytes, microglia, and macrophages to the lesion site. ${ }^{[95]}$ On the other hand, astrocytes are described as being responsible for a successful remyelination through the regulation of the clearance of myelin debris ${ }^{[94]}$ and oligodendrogenesis in the lesion site [Table 2]. ${ }^{[93]}$ Astrocytes promote OPC migration, proliferation, and differentiation after demyelination by secreting several factors, which have an impact on myelin repair. ${ }^{[93]}$ In fact, several cytokines and chemokines produced by microglia, macrophages, and astrocytes in response to brain injury have been described as having an essential 


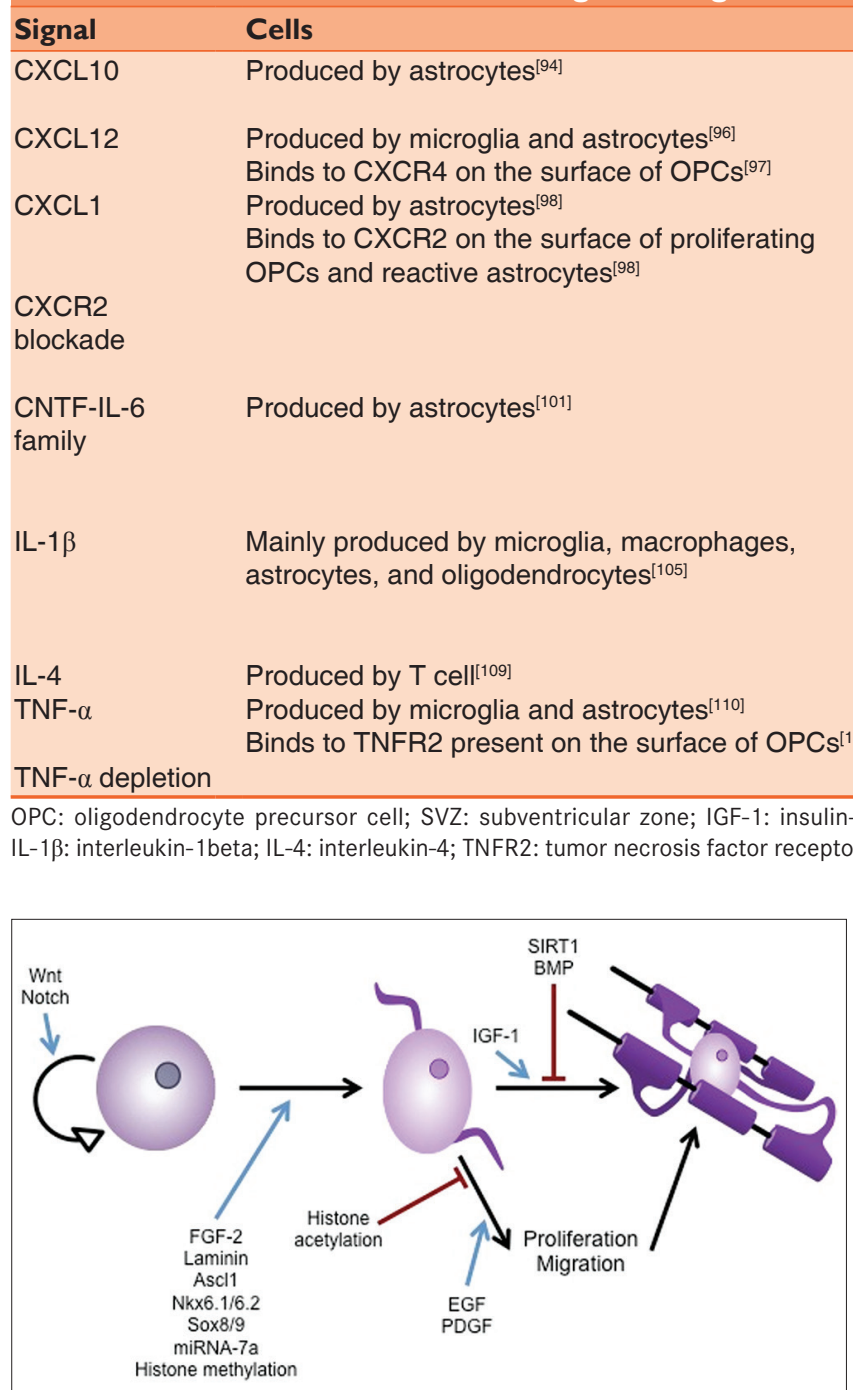

Figure 4: Schematic representation of modulators of oligodendrogenesis in the adult brain. Wnt and Notch positively regulate neural stem cells self-renewal. Fibroblast growth factor-2, laminin, Ascl1, Nkx6.1/6.2, Sox 8/9, miRNA-7a and histone methylation positively modulate oligodendrocyte fate. Histone acetylation inhibits while epidermal growth factor and platelet-derived growth factor receptor $\alpha$ promotes oligodendrocyte precursor cell differentiation. Sirt1 and bone morphogenic proteins block while Insulin-like growth factor- 1 stimulates oligodendrocyte differentiation

role in the repair process, such as regulating OPC proliferation, migration, and differentiation into new myelinating oligodendrocytes [Table 2]. In other words, the inflammatory response seems not merely a cause for demyelination but rather a prerequisite for a successful remyelination.

With the progression of the demyelinating disease, or even with ageing, there is an impairment of the remyelination process due to a decrease of pro-oligodendrogenic signals and an increase of anti-oligodendrogenic signals from immune cells that compromises oligodendrocyte maturation and myelination, leading to high inflammation and cell death. ${ }^{[42,106,112]}$

\section{Function}

Promotes the migration of microglia and macrophages to the demyelinated areas to phagocytose the damaged myelin sheaths ${ }^{[94}$ Mobilizes and stimulates OPC differentiation into oligodendrocytes ${ }^{[96]}$

Prevents apoptosis of oligodendrocytes in demyelinated white matter areas ${ }^{[99]}$

\section{Enhances OPC differentiation ${ }^{[100]}$}

Reduces the extent of microglia activation and the number of infiltrating inflammatory cells ${ }^{[100]}$

Protects axons and OPCs ${ }^{[102,103]}$

Controls SVZ-derived progenitor cells and OPC mobilization and migration toward demyelinated areas ${ }^{[104]}$

Promotes oligodendrocyte maturation ${ }^{[93]}$

Promotes OPC protection and differentiation by stimulating microglia, macrophages, and astrocytes to produce growth-promoting factors, such as IGF-1, and also TNF- $\alpha$ and nitric oxide $^{[106-108]}$

Promotes microglia activation which produces IGF-1[109] Promotes proliferation and accumulation of OPCs ${ }^{[111]}$

Decreases proliferation of NG2+immature oligodendrocytes ${ }^{[111]}$ 


\section{REFERENCES}

1. El Waly B, Macchi M, Cayre M, Durbec P. Oligodendrogenesis in the normal and pathological central nervous system. Front Neurosci 2014;8:145

2. Bergles DE, Jabs R, Steinhauser C. Neuron-glia synapses in the brain. Brain Res Rev 2010;63:130-7.

3. Zhao C, Fancy SP, Magy L, Urwin JE, Franklin RJ. Stem cells, progenitors and myelin repair. J Anat 2005;207:251-8.

4. Kaneko N, Kako E, Sawamoto K. Enhancement of ventricular-subventricular zone-derived neurogenesis and oligodendrogenesis by erythropoietin and its derivatives. Front Cell Neurosci 2013;7:235.

5. Menn B, Garcia-Verdugo JM, Yaschine C, Gonzalez-Perez O, Rowitch D, Alvarez-Buylla A. Origin of oligodendrocytes in the subventricular zone of the adult brain. J Neurosci 2006;26:7907-18.

6. Nishiyama A, Komitova M, Suzuki R, Zhu X. Polydendrocytes (NG2 cells): multifunctional cells with lineage plasticity. Nat Rev Neurosci 2009;10:9-22.

7. Fancy SP, Zhao C, Franklin RJ. Increased expression of Nkx2.2 and Olig2 identifies reactive oligodendrocyte progenitor cells responding to demyelination in the adult CNS. Mol Cell Neurosci 2004;27:247-54.

8. Polito A, Reynolds R. NG2-expressing cells as oligodendrocyte progenitors in the normal and demyelinated adult central nervous system. $J$ Anat 2005;207:707-16.

9. Ong WY, Levine JM. A light and electron microscopic study of NG2 chondroitin sulfate proteoglycan-positive oligodendrocyte precursor cells in the normal and kainate-lesioned rat hippocampus. Neuroscience 1999:92:83-95.

10. Spassky N, Olivier C, Cobos I, LeBras B, Goujet-Zalc C, Martinez S, Zalc B, Thomas JL. The early steps of oligodendrogenesis: insights from the study of the plp lineage in the brain of chicks and rodents. Dev Neurosci 2001;23:318-26.

11. Tekki-Kessaris N, Woodruff R, Hall AC, Gaffield W, Kimura S, Stiles CD, Rowitch DH, Richardson WD. Hedgehog-dependent oligodendrocyte lineage specification in the telencephalon. Development 2001;128:2545-54.

12. Kessaris N, Fogarty M, Iannarelli P, Grist M, Wegner M, Richardson WD. Competing waves of oligodendrocytes in the forebrain and postnatal elimination of an embryonic lineage. Nat Neurosci 2006;9:173-9.

13. Ortega F, Gascon S, Masserdotti G, Deshpande A, Simon C, Fischer J, Dimou L, Chichung Lie D, Schroeder T, Berninger B. Oligodendrogliogenic and neurogenic adult subependymal zone neural stem cells constitute distinct lineages and exhibit differential responsiveness to Wnt signalling. Nat Cell Biol 2013;15:602-13.

14. Jakovcevski I, Zecevic N. Sequence of oligodendrocyte development in the human fetal telencephalon. Glia 2005;49:480-91.

15. Jakovcevski I, Filipovic R, Mo Z, Rakic S, Zecevic N. Oligodendrocyte development and the onset of myelination in the human fetal brain. Front Neuroanat 2009:3:5.

16. Tripathi RB, Clarke LE, Burzomato V, Kessaris N, Anderson PN, Attwell D, Richardson WD. Dorsally and ventrally derived oligodendrocytes have similar electrical properties but myelinate preferred tracts. J Neurosci 2011;31:6809-19.

17. Dawson MR, Polito A, Levine JM, Reynolds R. NG2-expressing glial progenitor cells: an abundant and widespread population of cycling cells in the adult rat CNS. Mol Cell Neurosci 2003;24:476-88.

18. Franklin RJ, Ffrench-Constant C. Remyelination in the CNS: from biology to therapy. Nat Rev Neurosci 2008;9:839-55.

19. Psachoulia K, Jamen F, Young KM, Richardson WD. Cell cycle dynamics of NG2 cells in the postnatal and ageing brain. Neuron Glia Biol 2009;5:57-67.

20. Wolswijk G, Noble M. Identification of an adult-specific glial progenitor cell. Development 1989;105:387-400.

21. Wren D, Wolswijk G, Noble M. In vitro analysis of the origin and maintenance of O-2Aadult progenitor cells. $J$ Cell Biol 1992;116:167-76.
22. Dimou L, Simon C, Kirchhoff F, Takebayashi H, Gotz M. Progeny of Olig2-expressing progenitors in the gray and white matter of the adult mouse cerebral cortex. J Neurosci 2008;28:10434-42.

23. Rivers LE, Young KM, Rizzi M, Jamen F, Psachoulia K, Wade A, Kessaris N, Richardson WD. PDGFRA/NG2 glia generate myelinating oligodendrocytes and piriform projection neurons in adult mice. Nat Neurosci 2008;11:1392-401.

24. Calver AR, Hall AC, Yu WP, Walsh FS, Heath JK, Betsholtz C, Richardson WD. Oligodendrocyte population dynamics and the role of PDGF in vivo. Neuron 1998;20:869-82.

25. Hill RA, Patel KD, Medved J, Reiss AM, Nishiyama A. NG2 cells in white matter but not gray matter proliferate in response to PDGF. J Neurosci 2013;33:14558-66.

26. Karadottir R, Hamilton NB, Bakiri Y, Attwell D. Spiking and nonspiking classes of oligodendrocyte precursor glia in CNS white matter. Nat Neurosci 2008;11:450-6.

27. Yuan X, Chittajallu R, Belachew S, Anderson S, McBain CJ, Gallo V. Expression of the green fluorescent protein in the oligodendrocyte lineage: a transgenic mouse for developmental and physiological studies. J Neurosci Res 2002;70:529-45.

28. Vigano F, Mobius W, Gotz M, Dimou L. Transplantation reveals regional differences in oligodendrocyte differentiation in the adult brain. Nat Neurosci 2013;16:1370-2.

29. Zhao C, Fancy SP, Kotter MR, Li WW, Franklin RJ. Mechanisms of CNS remyelination--the key to therapeutic advances. J Neurol Sci 2005;233:87-91.

30. Picard-Riera N, Nait-Oumesmar B, Baron-Van Evercooren A Endogenous adult neural stem cells: limits and potential to repair the injured central nervous system. J Neurosci Res 2004;76:223-31.

31. Song H, Stevens CF, Gage FH. Astroglia induce neurogenesis from adult neural stem cells. Nature 2002;417:39-44.

32. Faigle $\mathrm{R}$, Song $\mathrm{H}$. Signaling mechanisms regulating adult neural stem cells and neurogenesis. Biochim Biophys Acta 2013;1830:2435-48.

33. Paspala SA, Murthy TV, Mahaboob VS, Habeeb MA. Pluripotent stem cells-a review of the current status in neural regeneration. Neurol India 2011;59:558-65.

34. Bergstrom T, Forsberg-Nilsson K. Neural stem cells: brain building blocks and beyond. Ups J Med Sci 2012;117:132-42.

35. Kirschenbaum B, Doetsch F, Lois C, Alvarez-Buylla A. Adult subventricular zone neuronal precursors continue to proliferate and migrate in the absence of the olfactory bulb. $J$ Neurosci 1999;19:2171-80.

36. Doetsch F, Caille I, Lim DA, Garcia-Verdugo JM, Alvarez-Buylla A Subventricular zone astrocytes are neural stem cells in the adult mammalian brain. Cell 1999;97:703-16.

37. Lois C, Alvarez-Buylla A. Proliferating subventricular zone cells in the adult mammalian forebrain can differentiate into neurons and glia. Proc Natl Acad Sci U S A 1993;90:2074-7.

38. Cayre M, Canoll P, Goldman JE. Cell migration in the normal and pathological postnatal mammalian brain. Prog Neurobiol 2009;88:41-63.

39. Suzuki SO, Goldman JE. Multiple cell populations in the early postnatal subventricular zone take distinct migratory pathways: a dynamic study of glial and neuronal progenitor migration. JNeurosci 2003;23:4240-50.

40. Colak D, Mori T, Brill MS, Pfeifer A, Falk S, Deng C, Monteiro R, Mummery C, Sommer L, Gotz M. Adult neurogenesis requires Smad4-mediated bone morphogenic protein signaling in stem cells. J Neurosci 2008;28:434-46.

41. Jablonska B, Aguirre A, Raymond M, Szabo G, Kitabatake Y, Sailor KA, Ming GL, Song H, Gallo V. Chordin-induced lineage plasticity of adult SVZ neuroblasts after demyelination. Nat Neurosci 2010;13:541-50.

42. Maki T, Liang AC, Miyamoto N, Lo EH, Arai K. Mechanisms of oligodendrocyte regeneration from ventricular-subventricular zone-derived progenitor cells in white matter diseases. Front Cell Neurosci 2013;7:275.

43. Falcao AM, Marques F, Novais A, Sousa N, Palha JA, Sousa JC. The path from the choroid plexus to the subventricular zone: go with the flow! Front Cell Neurosci 2012;6:34. 
44. Fuentealba LC, Obernier K, Alvarez-Buylla A. Adult neural stem cells bridge their niche. Cell Stem Cell 2012;10:698-708.

45. Tavazoie M, Van der Veken L, Silva-Vargas V, Louissaint M, Colonna L, Zaidi B, Garcia-Verdugo JM, Doetsch F. A specialized vascular niche for adult neural stem cells. Cell Stem Cell 2008;3:279-88.

46. Shen Q, Wang Y, Kokovay E, Lin G, Chuang SM, Goderie SK, Roysam B, Temple S. Adult SVZ stem cells lie in a vascular niche: a quantitative analysis of niche cell-cell interactions. Cell Stem Cell 2008;3:289-300.

47. Mitchell K, Yang HY, Berk JD, Tran JH, Iadarola MJ. Monocyte chemoattractant protein-1 in the choroid plexus: a potential link between vascular pro-inflammatory mediators and the CNS during peripheral tissue inflammation. Neuroscience 2009;158:885-95.

48. Marques F, Sousa JC, Correia-Neves M, Oliveira P, Sousa N, Palha JA. The choroid plexus response to peripheral inflammatory stimulus. Neuroscience 2007;144:424-30.

49. Goldman SA, Chen Z. Perivascular instruction of cell genesis and fate in the adult brain. Nat Neurosci 2011;14:1382-9.

50. Masahira N, Takebayashi H, Ono K, Watanabe K, Ding L, Furusho M, Ogawa Y, Nabeshima Y, Alvarez-Buylla A, Shimizu K, Ikenaka K. Olig2-positive progenitors in the embryonic spinal cord give rise not only to motoneurons and oligodendrocytes, but also to a subset of astrocytes and ependymal cells. Dev Biol 2006;293:358-69.

51. Dessaud E, Ribes V, Balaskas N, Yang LL, Pierani A, Kicheva A, Novitch BG, Briscoe J, Sasai N. Dynamic assignment and maintenance of positional identity in the ventral neural tube by the morphogen sonic hedgehog. PLoS Biol 2010;8:e1000382.

52. Kim H, Shin J, Kim S, Poling J, Park HC, Appel B. Notch-regulated oligodendrocyte specification from radial glia in the spinal cord of zebrafish embryos. Dev Dyn 2008;237:2081-9.

53. See JM, Grinspan JB. Sending mixed signals: bone morphogenetic protein in myelination and demyelination. JNeuropathol Exp Neurol 2009;68:595-604

54. Chintawar S, Cayrol R, Antel J, Pandolfo M, Prat A. Blood-brain barrier promotes differentiation of human fetal neural precursor cells. Stem Cells 2009;27:838-46.

55. Plane JM, Andjelkovic AV, Keep RF, Parent JM. Intact and injured endothelial cells differentially modulate postnatal murine forebrain neural stem cells. Neurobiol Dis 2010;37:218-27.

56. Relucio J, Menezes MJ, Miyagoe-Suzuki Y, Takeda S, Colognato H. Laminin regulates postnatal oligodendrocyte production by promoting oligodendrocyte progenitor survival in the subventricular zone. Glia 2012;60:1451-67.

57. Jackson EL, Garcia-Verdugo JM, Gil-Perotin S, Roy M, Quinones-Hinojosa A, VandenBerg S, Alvarez-Buylla A. PDGFR alpha-positive B cells are neural stem cells in the adult SVZ that form glioma-like growths in response to increased PDGF signaling. Neuron 2006;51:187-99.

58. Rafalski VA, Ho PP, Brett JO, Ucar D, Dugas JC, Pollina EA, Chow LM, Ibrahim A, Baker SJ, Barres BA, Steinman L, Brunet A. Expansion of oligodendrocyte progenitor cells following SIRT1 inactivation in the adult brain. Nat Cell Biol 2013;15:614-24

59. Aguirre A, Dupree JL, Mangin JM, Gallo V. A functional role for EGFR signaling in myelination and remyelination. Nat Neurosc 2007; 10:990-1002.

60. Gonzalez-Perez O, Alvarez-Buylla A. Oligodendrogenesis in the subventricular zone and the role of epidermal growth factor. Brain Res Rev 2011;67:147-56.

61. Hsieh J, Aimone JB, Kaspar BK, Kuwabara T, Nakashima K, Gage FH. IGF-I instructs multipotent adult neural progenitor cells to become oligodendrocytes. J Cell Biol 2004;164:111-22.

62. Qu Q, Sun G, Li W, Yang S, Ye P, Zhao C, Yu RT, Gage FH, Evans RM, Shi Y. Orphan nuclear receptor TLX activates Wnt/ beta-catenin signalling to stimulate neural stem cell proliferation and self-renewal. Nat Cell Biol 2010;12:31-40; sup pp 1-9.

63. Ables JL, Decarolis NA, Johnson MA, Rivera PD, Gao Z, Cooper DC, Radtke F, Hsieh J, Eisch AJ. Notch1 is required for maintenance of the reservoir of adult hippocampal stem cells. J Neurosci 2010;30:10484-92.
64. Imayoshi I, Sakamoto M, Yamaguchi M, Mori K, Kageyama R. Essential roles of Notch signaling in maintenance of neural stem cells in developing and adult brains. $J$ Neurosci 2010;30:3489-98

65. Ortega JA, Radonjic NV, Zecevic N. Sonic hedgehog promotes generation and maintenance of human forebrain Olig2 progenitors. Front Cell Neurosci 2013;7:254.

66. Lim DA, Tramontin AD, Trevejo JM, Herrera DG, Garcia-Verdugo JM Alvarez-Buylla A. Noggin antagonizes BMP signaling to create a niche for adult neurogenesis. Neuron 2000;28:713-26.

67. Doetsch F, Petreanu L, Caille I, Garcia-Verdugo JM, Alvarez-Buylla A EGF converts transit-amplifying neurogenic precursors in the adult brain into multipotent stem cells. Neuron 2002;36:1021-34.

68. Rai KS, Hattiangady B, Shetty AK. Enhanced production and dendritic growth of new dentate granule cells in the middle-aged hippocampus following intracerebroventricular FGF-2 infusions. Eur J Neurosci 2007;26:1765-79.

69. Nakatani H, Martin E, Hassani H, Clavairoly A, Maire CL, Viadieu A, Kerninon C, Delmasure A, Frah M, Weber M, Nakafuku M, Zalc B, Thomas JL, Guillemot F, Nait-Oumesmar B, Parras C. Ascl1/Mash1 promotes brain oligodendrogenesis during myelination and remyelination. J Neurosci 2013;33:9752-68.

70. Cai J, Qi Y, Hu X, Tan M, Liu Z, Zhang J, Li Q, Sander M, Qiu M. Generation of oligodendrocyte precursor cells from mouse dorsal spinal cord independent of Nkx6 regulation and Shh signaling. Neuron 2005;45:41-53.

71. Vallstedt A, Klos JM, Ericson J. Multiple dorsoventral origins of oligodendrocyte generation in the spinal cord and hindbrain. Neuron 2005;45:55-67.

72. Stolt CC, Lommes P, Sock E, Chaboissier MC, Schedl A, Wegner M The Sox9 transcription factor determines glial fate choice in the developing spinal cord. Genes Dev 2003;17:1677-89.

73. Zhao X, Wu J, Zheng M, Gao F, Ju G. Specification and maintenance of oligodendrocyte precursor cells from neural progenitor cells involvement of microRNA-7a. Mol Biol Cell 2012;23:2867-78.

74. Sher F, Rossler R, Brouwer N, Balasubramaniyan V, Boddeke E, Copray S. Differentiation of neural stem cells into oligodendrocytes: involvement of the polycomb group protein Ezh2. Stem Cells 2008;26:2875-83.

75. Lyssiotis CA, Walker J, Wu C, Kondo T, Schultz PG, Wu X Inhibition of histone deacetylase activity induces developmental plasticity in oligodendrocyte precursor cells. Proc Natl Acad Sci U S A 2007;104:14982-7.

76. Lu QR, Sun T, Zhu Z, Ma N, Garcia M, Stiles CD, Rowitch DH Common developmental requirement for Olig function indicates a motor neuron/oligodendrocyte connection. Cell 2002;109:75-86.

77. Ligon KL, Kesari S, Kitada M, Sun T, Arnett HA, Alberta JA, Anderson DJ, Stiles CD, Rowitch DH. Development of NG2 neural progenitor cells requires Olig gene function. Proc Natl Acad Sci U S A 2006;103:7853-8.

78. Zhou Q, Anderson DJ. The bHLH transcription factors OLIG2 and OLIG1 couple neuronal and glial subtype specification. Cell 2002;109:61-73.

79. Maire CL, Wegener A, Kerninon C, Nait Oumesmar B. Gain-of-function of Olig transcription factors enhances oligodendrogenesis and myelination. Stem Cells 2010;28:1611-22.

80. Najm FJ, Lager AM, Zaremba A, Wyatt K, Caprariello AV, Factor DC, Karl RT, Maeda T, Miller RH, Tesar PJ. Transcription factor-mediated reprogramming of fibroblasts to expandable, myelinogenic oligodendrocyte progenitor cells. Nat Biotechnol 2013;31:426-33.

81. Yang $\mathrm{N}$, Zuchero JB, Ahlenius $\mathrm{H}$, Marro S, Ng YH, Vierbuchen T, Hawkins JS, Geissler R, Barres BA, Wernig M. Generation of oligodendroglial cells by direct lineage conversion. Nat Biotechnol 2013;31:434-9.

82. Parras CM, Hunt C, Sugimori M, Nakafuku M, Rowitch D, Guillemot $\mathrm{F}$. The proneural gene Mash1 specifies an early population of telencephalic oligodendrocytes. J Neurosci 2007;27:4233-42.

83. Sugimori M, Nagao M, Parras CM, Nakatani H, Lebel M, Guillemot F, Nakafuku M. Ascl1 is required for oligodendrocyte development in the spinal cord. Development 2008;135:1271-81. 
84. Richardson WD, Kessaris N, Pringle N. Oligodendrocyte wars. Nat Rev Neurosci 2006; 7:11-8.

85. Liu J, Casaccia P. Epigenetic regulation of oligodendrocyte identity. Trends Neurosci 2010;33:193-201.

86. Amor S, Puentes F, Baker D, van der Valk P. Inflammation in neurodegenerative diseases. Immunology 2010;129:154-69.

87. Minagar A, Shapshak P, Fujimura R, Ownby R, Heyes M, Eisdorfer C. The role of macrophage/microglia and astrocytes in the pathogenesis of three neurologic disorders: HIV-associated dementia, Alzheimer disease, and multiple sclerosis. J Neurol Sci 2002;202:13-23.

88. Streit WJ, Mrak RE, Griffin WS. Microglia and neuroinflammation: a pathological perspective. J Neuroinflammation 2004;1:14.

89. Giunti D, Parodi B, Cordano C, Uccelli A, Kerlero de Rosbo N. Can we switch microglia's phenotype to foster neuroprotection? Focus on multiple sclerosis. Immunology 2014;141:328-39.

90. Kotter MR, Zhao C, van Rooijen N, Franklin RJ. Macrophage-depletion induced impairment of experimental CNS remyelination is associated with a reduced oligodendrocyte progenitor cell response and altered growth factor expression. Neurobiol Dis 2005;18:166-75.

91. Olah M, Amor S, Brouwer N, Vinet J, Eggen B, Biber K, Boddeke HW. Identification of a microglia phenotype supportive of remyelination. Glia 2012;60:306-21.

92. Perez Estrada C, Covacu R, Sankavaram SR, Svensson M, Brundin L. Oxidative stress increases neurogenesis and oligodendrogenesis in adult neural progenitor cells. Stem Cells Dev 2014;23:2311-27.

93. Moore CS, Abdullah SL, Brown A, Arulpragasam A, Crocker SJ. How factors secreted from astrocytes impact myelin repair. J Neurosci Res 2011;89:13-21.

94. Skripuletz T, Hackstette D, Bauer K, Gudi V, Pul R, Voss E, Berger K, Kipp M, Baumgartner W, Stangel M. Astrocytes regulate myelin clearance through recruitment of microglia during cuprizone-induced demyelination. Brain 2013;136:147-67.

95. Williams A, Piaton G, Lubetzki C. Astrocytes--friends or foes in multiple sclerosis? Glia 2007;55:1300-12.

96. Patel JR, McCandless EE, Dorsey D, Klein RS. CXCR4 promotes differentiation of oligodendrocyte progenitors and remyelination. Proc Natl Acad Sci U S A 2010;107:11062-7.

97. Maysami S, Nguyen D, Zobel F, Pitz C, Heine S, Hopfner M, Stangel M. Modulation of rat oligodendrocyte precursor cells by the chemokine CXCL12. Neuroreport 2006;17:1187-90.

98. Omari KM, John G, Lango R, Raine CS. Role for CXCR2 and CXCL1 on glia in multiple sclerosis. Glia 2006;53:24-31.

99. Hosking MP, Tirotta E, Ransohoff RM, Lane TE. CXCR2 signaling protects oligodendrocytes and restricts demyelination in a mouse model of viral-induced demyelination. PLoS One 2010;5:e11340.

100. Kerstetter AE, Padovani-Claudio DA, Bai L, Miller RH. Inhibition of CXCR2 signaling promotes recovery in models of multiple sclerosis. Exp Neurol 2009;220:44-56

101. Albrecht PJ, Murtie JC, Ness JK, Redwine JM, Enterline JR, Armstrong RC, Levison SW. Astrocytes produce CNTF during the remyelination phase of viral-induced spinal cord demyelination to stimulate FGF-2 production. Neurobiol Dis 2003;13:89-101.

102. Dutta R, McDonough J, Chang A, Swamy L, Siu A, Kidd GJ, Rudick R, Mirnics K, Trapp BD. Activation of the ciliary neurotrophic factor (CNTF) signalling pathway in cortical neurons of multiple sclerosis patients. Brain 2007;130:2566-76.

103. Linker RA, Maurer M, Gaupp S, Martini R, Holtmann B, Giess R, Rieckmann P, Lassmann H, Toyka KV, Sendtner M, Gold R. CNTF is a major protective factor in demyelinating $\mathrm{CNS}$ disease: a neurotrophic cytokine as modulator in neuroinflammation. Nat Med 2002;8:620-4.

104. Vernerey J, Macchi M, Magalon K, Cayre M, Durbec P. Ciliary neurotrophic factor controls progenitor migration during remyelination in the adult rodent brain. JNeurosci 2013;33:3240-50.

105. Sairanen TR, Lindsberg PJ, Brenner M, Siren AL. Global forebrain ischemia results in differential cellular expression of interleukin-1beta (IL-1beta) and its receptor at mRNA and protein level. J Cereb Blood Flow Metab 1997;17:1107-20

106. Mason JL, Suzuki K, Chaplin DD, Matsushima GK. Interleukin-1beta promotes repair of the CNS. J Neurosci 2001;21:7046-52.

107. Merrill JE. Effects of interleukin- 1 and tumor necrosis factor-alpha on astrocytes, microglia, oligodendrocytes, and glial precursors in vitro. Dev Neurosci 1991;13:130-7.

108. Shigemoto-Mogami Y, Hoshikawa K, Goldman JE, Sekino Y, Sato K. Microglia enhance neurogenesis and oligodendrogenesis in the early postnatal subventricular zone. J Neurosci 2014;34:2231-43.

109. Butovsky O, Ziv Y, Schwartz A, Landa G, Talpalar AE, Pluchino S, Martino G, Schwartz M. Microglia activated by IL-4 or IFN-gamma differentially induce neurogenesis and oligodendrogenesis from adult stem/progenitor cells. Mol Cell Neurosci 2006;31:149-60.

110. Shohami E, Ginis I, Hallenbeck JM. Dual role of tumor necrosis factor alpha in brain injury. Cytokine Growth Factor Rev 1999;10:119-30.

111. Arnett HA, Mason J, Marino M, Suzuki K, Matsushima GK, Ting JP. TNF alpha promotes proliferation of oligodendrocyte progenitors and remyelination. Nat Neurosci 2001;4:1116-22.

112. Kotter MR, Stadelmann C, Hartung HP. Enhancing remyelination in disease-can we wrap it up? Brain 2011;134:1882-900. 